Original Article

\title{
Detection of antibodies to recombinant truncated flagellin and sonicated whole cell antigen of Burkholderia pseudomallei in acute melioidosis and in healthy Bangladeshi individuals
}

\author{
Md. Shariful Alam Jilani ${ }^{1}$, Tang Thean Hock ${ }^{2}$, Sraboni Mazumder ${ }^{1}$, Fahmida Rahman ${ }^{1}$, Md. Mohiuddin ${ }^{1}$, \\ Chowdhury Rafiqul Ahsan ${ }^{3}$, Jalaluddin Ashraful Haq ${ }^{1^{*}}$ \\ ${ }^{1}$ Department of Microbiology, Ibrahim Medical College; ${ }^{2}$ Advanced Medical \& Dental Institute (AMDI), \\ Universiti Sains Malaysia, 13200 Bertam, Kepala Batas, Pulau Pinang, Malaysia; ${ }^{3}$ Department of \\ Microbiology, University of Dhaka
}

\begin{abstract}
Background and objectives: Several types of Burkholderia pseudomallei antigens have been used to determine the antibody response in acute and asymptomatic cases. In the present study, we have detected immunoglobulin G (IgG) antibody to recombinant truncated flagellin antigen (RTFA) of $B$. pseudomallei in the sera of acute melioidosis cases and healthy individuals from melioidosis endemic areas of Bangladesh by indirect enzyme-linked immunosorbent assay (ELISA). In parallel, IgG antibody to sonicated whole cell antigen (SWCA) of B. pseudomallei was determined to compare with anti-RTFA antibody.
\end{abstract}

Methodology: Serum samples from culture confirmed melioidosis cases and from healthy individuals aged 21 years and above residing in melioidosis endemic rural areas were included in the study. Serum IgG antibody to RTFA and SWCA of B. pseudomallei was determined by indirect ELISA.

Results: Out of 8 culture confirmed acute melioidosis cases, 7 (87.5\%) and 8 (100\%) were positive for anti-B. pseudomallei IgG antibodies by RTFA and SWCA methods respectively. Among 361 healthy individuals, the rate of seropositivity by RTFA-ELISA was significantly less than that of SWCA-ELISA (16.1\% versus $26.8 \%$; $p=0.001)$. The mean optical density (OD) of RTFA-ELISA of positive cases was significantly less than that of SWCA-ELISA in both melioidosis and healthy individuals $(0.79 \pm 0.11$ versus $2.4 \pm 0.08, p=0.0001 ; 0.67 \pm 0.01$ versus $1.27 \pm 0.02, p=$ 0.0001 ). The sensitivity and specificity of RTFA-ELISA were $88.9 \%$ and $100 \%$ respectively.

Conclusion: Findings of the study suggest that multiple or combination of antigens should be used to study the seroprevalence of $B$. pseudomallei infection in a community. Also, prospective study is necessary to find out the duration of persistence of antibodies to different antigenic components of $B$. pseudomallei after exposure.

IMC J Med Sci 2020; 14(1): 010. EPub date: 31 May 2020

\section{Introduction}

Burkholderia pseudomallei is a gram negative bacillus and the causative agent of melioidosis. The organism is found in the soil and surface water of endemic areas and infects human by direct contact. Clinical disease includes localized or septicemia infection. But asymptomatic infection is also common [1]. The bacterium is able to remain quiescent or latent in the host for decades following primary infection while maintaining the potential to relapse to cause acute and fulminating disease after many years $[2,3]$. So, once considered

*Correspondence: J. Ashraful Haq, Department of Microbiology, Ibrahim Medical College, 1/A Ibrahim Sarani, Segunbagicha, Dhaka 1000, Bangladesh.Email: jahaq54@yahoo.com 
as obscurity, melioidosis is now recognized as an emerging disease of global importance. It is largely restricted to the Southeast Asia and Northern Australia, however, the disease has been increasingly reported in countries outside the AsiaPacific region including Bangladesh [4,5]. It was first reported in Bangladesh in 1964 [6]. Subsequently, substantial increase in sporadic cases were reported after $1988[4,7,8]$.

Several serological methods have been developed to diagnose the infection by $B$. pseudomallei in acute cases as well as to determine the status and magnitude of exposure to the organism in healthy individuals. The most commonly used serological method - the indirect hemagglutination test (IHA) has limited clinical value in regions of endemicity due to the high background antibody titers in healthy individuals, most likely the result of repeated environmental exposure to $B$. pseudomallei [9]. A critical limitation of this assay is the lack of standardization between laboratories with respect to the antigens used; the antigens remain poorly characterized and are likely to be variable between isolates [10]. The indirect immunofluorescence antibody test (IFAT) using whole $B$. pseudomallei cells as antigen was found to be sensitive and superior to IHA and requires only a day to obtain the results [11]. The only drawback is that IFAT requires a fluorescence microscope and skilled personnel which might not be readily available in rural endemic regions of South and Southeast Asia. ELISA is being considered more favorably as a rapid and reliable tool for detection of $B$. pseudomallei infection [12]. Various antigen preparations such as crude and purified exopolysaccharide (EPS) and lipopolysaccharide (LPS) outer membrane proteins (Omps) and Bip components of $B$. pseudomallei type III secretion system (TTSS-3) have been reported as potential candidate antigens to detect antibodies in infection by $B$. pseudomallei in an ELISA format $[12,13]$. However, crude or uncharacterized antigens of $B$. pseudomallei cross-react with antibodies induced by other bacterial infection, making the methods less specific. To avoid the cross reactivity, a recombinant truncated flagellin antigen was developed to identify $B$. pseudomallei-specific antibodies [14]. The truncated flagellin protein of $B$. pseudomallei was supposed to be devoid of cross reactive epitopes and would elicit specific antibodies.

The present study was undertaken to detect IgG antibody to recombinant truncated flagellin antigen (RTFA) and sonicated whole cell antigen (SWCA) of B. pseudomallei in the sera of acute melioidosis cases and healthy individuals from melioidosis endemic areas of Bangladesh by ELISA. The presence of IgG antibody to RFTA and SWCA in healthy individuals would provide evidence for extent of exposure of individuals to $B$. pseudomallei.

\section{Materials and methods}

The present study was carried out to determine the presence of anti-B. pseudomallei IgG antibody in acute melioidosis cases and in endemic healthy individuals. Serum IgG antibody to B. pseudomallei was determined by ELISA using RTFA and SWCA. Details of the methods are described below.

The Ethical Review Committee (ERC) of the Diabetic Association of Bangladesh (BADAS) approved the study. Informed written consent was obtained from all participants prior to collection of blood samples.

Serum samples: Serum samples in this study were collected from 361 healthy individuals aged 21 years and above residing in rural areas of two melioidosis endemic districts of Bangladesh. Eight serum samples from culture confirmed acute melioidosis cases admitted at BIRDEM General Hospital were included. Sera from 35 healthy newborn babies of Dhaka city who were presumed not to be exposed to $B$. pseudomallei were enrolled as negative control. About $2 \mathrm{ml}$ of venous blood was collected from each individual with proper aseptic technique.

Expression and preparation of recombinant flagellin: Plasmid PGEX4Y-2 containing recombinant flagellin protein of $B$. pseudomallei used for the study was kindly provided by Ya-Lei Chen, Department of Medical Technology, Fooyin University, Kaohsi-ung 83101, Taiwan, Republic of China [14].

Flagellia protein was over expressed from the plasmid pGEX4T-2 cloned with flagellin gene of $B$. pseudomallei and transformed into $E$. coli BL21 strain. For protein purification, positive clone 
chosen was inoculated into $100 \mathrm{ml}$ Luria Broth (LB) cultures and allowed to grow at $37^{\circ} \mathrm{C}$ until the $\mathrm{OD}_{600}$ reached about 0.5 to 0.6 , induced with 1.0 $\mathrm{mM}$ isopropyl- $\beta$-D-thiogalactopyranoside (IPTG) for about 4 hours. Cell pellet was resuspended in $10 \mathrm{ml}$ of ice cool lysis buffer ( $50 \mathrm{mM}$ Tris- $\mathrm{HCl}, \mathrm{pH} 7.5,300$ $\mathrm{mM} \mathrm{NaCl}, 10 \%$ glycerol, $1 \%$ Triton $\mathrm{X}-100)$ and subjected to sonication on the ice bath. The cell lysate was then centrifuged at $4000 \mathrm{~g}$ for 20 minutes at $4{ }^{\circ} \mathrm{C}$ and supernatant was discarded. 400 $\mu \mathrm{L}$ of $\mathrm{Ni}^{2+}$-NTA resin (Qiagen, $\mathrm{GmbH}$ ) was added to the supernatant and mixed at $4{ }^{\circ} \mathrm{C}$ for 2 hours on a rotator. Bound recombinant protein was collected from the resin by adding $10 \mathrm{mM}$ reduced glutathione. The purified antigen was reconstituted with sterile distilled water to make up to a concentration of $1 \mu \mathrm{g} / \mu \mathrm{l}$ and aliquoted for further use.

Preparation of SWCA: To prepare SWCA, $50 \mathrm{ml}$ of Trypticase Soya Broth (TSB) was inoculated with pure colonies of $B$. pseudomallei USM strain and incubated overnight at $37^{\circ} \mathrm{C}$. Organisms were harvested by centrifugation for 30 minutes at $4000 \mathrm{~g}$ at $10^{\circ} \mathrm{C}$. Pellets were suspended with $3 \mathrm{ml}$ of $25 \mathrm{mM}$ Tris-HCL (pH 7.4) and washed three times with Tris-HCL for 30 minutes at $4000 \mathrm{~g}$ at $10^{\circ} \mathrm{C}$. Deposited pellet, suspended in $5 \mathrm{ml}$ of ice-cold Tris$\mathrm{HCL}$, was sonicated at $40 \mathrm{~W}$ for 8 minutes in each pulse inside the assigned biosafety cabinet. Sonicated bacterial suspension was then centrifuged at $5000 \mathrm{xg}$ at $10^{\circ} \mathrm{C}$ for 30 minutes. After centrifugation, the supernatant containing the bacterial proteins was collected and its protein concentration was determined.

Determination of anti-B. pseudomallei IgG antibody by ELISA: Serum anti-B. pseudomallei IgG antibody was determined by an indirect ELISA as described by Voller et al [15]. The 96 well ELISA plate (Linbro, USA) was coated with $2.5 \mu \mathrm{g} / \mathrm{ml}$ of RTFA or $10 \mu \mathrm{g} / \mathrm{ml}$ of SWCA in $0.5 \mathrm{M}$ carbonate/ bicarbonate buffer ( $\mathrm{pH}$ 9.6). To each well $100 \mu \mathrm{l}$ volume of coating buffer was added and incubated overnight at $4^{\circ} \mathrm{C}$. The plate was washed three times with phosphate buffered saline-0.05\% Tween 20 (PBS-T, pH 7.4) and blocked by incubating for 2 hours with PBS-T containing $2 \%$ bovine serum albumin (BSA) at $37^{\circ} \mathrm{C}$. The plate was then washed three times with PBS-T. A volume of $100 \mu \mathrm{l}$ serum
(1:400 dilution for RTFA and 1:1600 dilution for SWCA) samples was added into each well and incubated for 4 hours at $37^{\circ} \mathrm{C}$. After washing with PBS-T three times, $100 \mu$ of horseradish peroxydase conjugated anti-human IgG antibodies (MP Biomedicals, USA) (1:4000 dilution) was added and incubated at $37^{\circ} \mathrm{C}$ for 2 hours. After washing three times with PBS-T, $50 \mu \mathrm{l}$ of tetramethylbenzidine (TMB) substrate was added to each well and incubated at room temperature for 30 minutes in dark. Then $50 \mu \mathrm{l}$ of $1 \mathrm{M}$ sulfuric acid was added in each well. The colour developed was measured by ELISA plate reader (Human ELISA Reader) at 450 $\mathrm{nm}$. Optimum concentration of the antigen (2.5 $\mu \mathrm{g} / \mathrm{ml}$ for RTFA and $10 \mu \mathrm{g} / \mathrm{ml}$ for SWCA) and serum dilution (1:400 dilution for RTFA and 1:1600 dilution for SWCA) were predetermined by checkerboard titrations.

Cut-off OD values for anti-B. pseudomallei IgG antibody against RTFA and SWCA were determined to designate $B$. pseudomallei seropositivity of the study population. ELISA was performed with sera from 35 healthy newborn babies of Dhaka city who were presumed not to be exposed to $B$. pseudomallei. The mean $\mathrm{OD}+3 \times \mathrm{SD}$ of these sera was taken as cut-off OD value to designate the case as seropositive. Table- 1 shows the calculated cutoff OD values for RTFA and SWCA based ELISA. Any sample showing OD above the cut-off OD value of more than 0.4 and 0.8 by respectively RTFA and SWCA based ELISA was considered positive and referred to as exposed to $B$. pseudomallei infection.

Table-1: Calculated cut-off OD values for ELISA using RTFA and SWCA

\begin{tabular}{lccc}
\hline Antigen & $\begin{array}{c}\text { Mean OD } \\
\text { value }\end{array}$ & SD & $\begin{array}{c}\text { Cut-off value } \\
\text { (Mean OD+3xSD) }\end{array}$ \\
\hline RTFA & 0.2 & 0.06 & 0.4 \\
SWCA & 0.2 & 0.2 & 0.8 \\
\hline
\end{tabular}

Note: $R T F A=$ recombinant truncated flagellin antigen; SWCA = sonicated whole cell antigen; $O D=$ optical density; $S D=$ standard deviation

\section{Results}

Total 8 serum samples from culture confirmed melioidosis cases and 361 serum samples from 
Table-2: Detection of anti-B. pseudomallei antibodies in melioidosis cases and in endemic healthy individuals by ELISA using RTFA and SWCA

\begin{tabular}{|c|c|c|c|c|c|c|c|}
\hline \multirow[t]{2}{*}{$\begin{array}{l}\text { Study } \\
\text { population }\end{array}$} & \multirow{2}{*}{$\begin{array}{c}\text { Total } \\
\text { sample } \\
\text { number }\end{array}$} & \multicolumn{3}{|c|}{$\begin{array}{l}\text { Anti-B. pseudomallei IgG positive by } \\
\text { ELISA with }\end{array}$} & \multicolumn{3}{|c|}{ Mean OD $\pm S E$ of } \\
\hline & & $\begin{array}{l}\text { RTFA } \\
\text { N (\%) }\end{array}$ & $\begin{array}{l}\text { SWCA } \\
\text { N (\%) }\end{array}$ & $\begin{array}{l}p \text { value } \\
\text { by } Z \text { test }\end{array}$ & $\begin{array}{l}\text { RTFA- } \\
\text { ELISA }\end{array}$ & $\begin{array}{l}\text { SWCA- } \\
\text { ELISA }\end{array}$ & $\begin{array}{l}p \text { value } \\
\text { by t test }\end{array}$ \\
\hline $\begin{array}{l}\text { Culture } \\
\text { positive } \\
\text { melioidosis } \\
\text { case }\end{array}$ & 8 & 7 (87.5) & $8(100)$ & 0.303 & $0.79 \pm 0.11$ & $2.4 \pm 0.08$ & 0.0001 \\
\hline $\begin{array}{l}\text { Healthy } \\
\text { individuals }\end{array}$ & 361 & $58(16.1)$ & $97(26.87)$ & 0.001 & $0.67 \pm 0.01$ & $1.27 \pm 0.02$ & 0.0001 \\
\hline
\end{tabular}

healthy individuals aged 21 years and above residing in melioidosis endemic rural areas were included in the study. Out of 8 culture confirmed acute melioidosis cases, 7 (87.5\%) and 8 (100\%) were positive for anti-B. pseudomallei IgG antibodies by RTFA and SWCA methods respectively (Table-2). The mean OD of RTFA based ELISA of positive cases was significantly less than that of SWCA-ELISA (0.79 \pm 0.11 vs. $2.4 \pm 0.08 ; p=0.0001)$.

Out of total 361 healthy individuals, 58 (16.1\%; 95\% $\mathrm{Cl}: 0.125,0.203)$ and 97 (26.87\%; 95\% Cl: 0.224, 0.318 ) individuals were positive for anti- $B$. pseudomallei IgG antibody by RTFA and SWCA based ELISA respectively. The rate of seropositivity by RTFA-ELISA was significantly less $(p=0.001)$ than that of SWCA-ELISA (Table-2).The mean OD values of RTFA and SWCA based ELISA were $0.67 \pm 0.01$ and $1.27 \pm 0.02$ respectively $(p=0.0001)$.

The sensitivity and specificity of RTFA-ELISA, when calculated, were $88.9 \%$ and $100 \%$ respectively and for SWCA-ELISA it was $100 \%$ and $97.9 \%$.

\section{Discussion}

Infection by $B$. pseudomallei can be detected by either culture, molecular or serological methods. These methods are usually employed to diagnose acute melioidosis cases. Apart from diagnosis of acute infection, serology is employed to assess the extent of exposure to particular organism in a community. Several antigens of B. pseudomallei have been employed for serodiagnosis of acute and past infection with varying results.

A previous study evaluated 4 purified $B$. pseudomallei recombinant proteins (TssD-5, Omp3, smBpF4 and Omp85) using ELISA as potential diagnostic agents for melioidosis. TssD-5 demonstrated the highest sensitivity of $71 \%$ followed by Omp3 (59\%), smBpF4 (41\%) and Omp85 (19\%). All 4 antigens showed equally high specificity (89-96\%). A combination of four antigens provided improved sensitivity of $88.2 \%$ and good specificity (96\%) [13]. Anuntagool et al. evaluated five different $B$. pseudomallei antigens including a 19.5-kDa antigen, a crude cell extract, a veronal extract, a 39.0-kDa antigen, and an immunoaffinitypurified antigen by indirect ELISA. The 19.5-kDa antigen exhibited the most satisfactory results, with $92 \%$ sensitivity and $91 \%$ specificity [16].

We determined anti-B. pseudomallei IgG antibody in culture confirmed melioidosis cases and in healthy population residing in melioidosis endemic rural area of Bangladesh, by ELISA using RTFA and SWCA of $B$. pseudomallei in an in-house indirect ELISA. The rate of positive cases by RTFA-ELISA was significantly less ( $16.1 \%$ versus $26.87 \%$ ) compared to cases by SWCA-ELISA among the healthy people from melioidosis endemic area. Also, we observed lower mean OD values in both acute melioidosis 
and healthy cases by RTFA-ELISA than SWCA-ELISA indicating presence of less concentration of antibodies or reactants in serum against RTFA than SWCA. Similar low OD or absorbance (mean OD 0.4 ) was observed in culture confirmed melioidosis cases against truncated flagellin fragment [17]. We also presume that the antibody to RTFA might decline earlier overtime following exposure to $B$. pseudomallei. Also RTFA-ELISA detected antibody produced only against flagellar proteins instead of proteins from whole cell. But in case of SWCA, the antibodies detected were a mixture of antibodies against several antigenic components of the $B$. pseudomallei some of which might be long persisting against specific proteins. It appears that the rate of positivity of anti-B. pseudomallei antibody might vary depending on the assay method and antigen used in the serological assays. Therefore, prospective study should be undertaken to find out the duration of persistence of antibodies to $B$. pseudomallei flagellar proteins as well as to other cellular components following exposure.

High seropositivity rate in healthy population has been reported from other countries of the region. The seroprevalence rate of $B$. pseudomallei among the healthy people in Haiti was found as $9.8 \%$ by lipopolysaccharide based ELISA [18]. Another study reported $29 \%$ seropositivity among the adults in coastal areas in Southwestern India by indirect hemagglutination assay (IHA) using polysaccharide antigens of $B$. pseudomallei [19]. In a previous study conducted on more than 900 people in 2016, we found $21.5 \%$ of the study population as positive for anti-B. pseudomallei antibody by SWCA-ELISA [8]. The sensitivity and specificity of our RTFA-ELISA were $88.9 \%$ and $100 \%$ respectively. Similar range of sensitivity and specificity of flagellar protein based ELISA was reported by other studies [14,17].

The findings of the present study indicate that multiple or combination of antigens should be used to determine the actual presence of antibody to $B$. pseudomallei in seroprevalence study in a community.

\section{Acknowledgment}

We are thankful to Dr. Ya-Lei Chen, Department of Medical Technology, Fooyin University, Kaohsi-ung 83101, Taiwan, Republic of China, for kindly providing the Plasmid pGEX4Y-2 containing recombinant flagellin protein of $B$. pseudomallei.

\section{Competing interest}

The authors hereby, declare that no conflict of interest exists.

\section{Funding}

The study was partly funded by Ibrahim Medical College.

\section{References}

1. Cheng AC, Currie BJ. Melioidosis: epidemiology, pathophysiology, and management. Clin Microbiol Rev. 2005; 18(2): 383-416.

2. Ngauy V, Lemeshev Y, Sadkowski L, Crawford G. Cutaneous melioidosis in a man who was taken as a prisoner of war by the Japanese during world war II. J Clin Microbiol. 2005; 43(2): 970-972.

3. Puthucheary SD, Nathan SA. Comparison by electron microscopy of intracellular events and survival of Burkholderia pseudomallei in monocytes from normal subjects and patients with melioidosis. Singapore Med J 2006; 47: 697-703.

4. Barai L, Jilani MSA, Haq JA. Melioidosis - case reports and review of cases recorded among Bangladeshi population from 1988-2014. IMC J Med Sci. 2014; 8(1): 25-31.

5. Jilani MSA, Haq JA. Melioidosis in Bangladesh a disease yet to be explored. IMC J Med Sci. 2010; 4(1): i-ii.

6. Maegraith BG, Leithead CS. Melioidosis: A case-report. Lancet. 1964; 1: 862-863.

7. Struelens MJ, Mondol G, Bennish M, Dance DA. Melioidosis in Bangladesh: A case report. Trans $R$ Soc Trop Med Hyg. 1988; 82: 777-778.

8. Jilani MSA, Robayet JA, Mohiuddin M, Hasan MR, Ahsan CR, Haq JA. Burkholderia pseudomallei: Its detection in soil and seroprevalence in Bangladesh. PLOS Negl Trop Dis. 2016; 10: e0004301. 
9. Zysk G, Splettstosser WD, Neubauer H. A review on melioidosis with special respect on molecular and immunological diagnostic techniques. Clin Lab. 2000; 46(3-4): 119-130.

10. Anuntagool N, Naigowit $P$, Petkanchanapong V, Aramsri $P$, Panichakul T, Sirisinha S. Monoclonal antibody-based rapid identification of Burkholderia pseudomallei in blood culture fluid from patients with community-acquired septicaemia. J Med Microbiol. 2000, 49(12): 1075-1078.

11. Vadivelu J, Puthucheary SD, Gendeh GS, Parasakthi N. Serodiagnosis of melioidosis in Malaysia. Singapore Med J. 1995; 36(3): 299-302.

12. Druar C, Yu F, Barnes JL, Okinaka RT, Chantratita N, Beg $S$, et al. Evaluating Burkholderia pseudomallei Bip proteins as vaccines and Bip antibodies as detection agents. FEMS Immunol Med Microbiol. 2008; 52(1): 78-87.

13. Hara Y, Chin CY, Mohamed R, Puthucheary SD, Nathan S. Multiple-antigen ELISA for melioidosis - a novel approach to the improved serodiagnosis of melioidosis. BMC Infectious Diseases. 2013; 13:165.

14. Chen YS, Shiuan D, Chen SC, Chye SM, Chen YL. Recombinant truncated flagellin of Burkholderia pseudomallei as a molecular probe for diagnosis of melioidosis. Clin Diagn Lab Immunol. 2003; 10(3): 423-425.

15. Voller A, Bartlett A, Bidwell DE. Enzyme immunoassays with special reference to ELISA techniques. J Clin Pathol. 1978; 31(6): 507-520.

16. Anuntagool N, Rugdech $P$, Sirisinha $S$. Identification of specific antigens of Pseudomonas pseudomallei and evaluation of their efficacies for diagnosis of melioidosis. J Clin Microbiol. 1993; 31: 1232-1236.

17. Wajanarogana S, Kritsiriwuthinan K. Efficacy of indirect ELISA for serodiagnosis of melioidosis using immunodominant antigens from nonpathogenic Burkholderia thailandensis. Springer Plus. 2016; 5: 1814.

18. Weppelmann TA, Norris $M H$, von Fricken $M E$, Khan MSR, Okech BA, Cannella AP, et al. Seroepidemiology of Burkholderia pseudomallei, etiologic agent of melioidosis, in the Ouest and Sud-Est Departments of Haiti. Am J Trop Med Hyg. 2018; 99(5): 1222-1228.

19. Vandana KE, Mukhopadhyay C, Tellapragada C, Kamath A, Tipre $M$, Bhat $V$, et al. Seroprevalence of Burkholderia pseudomallei among adults in coastal areas in Southwestern India. PLOS Negl Trop Dis. 2016; 10(4): e0004610. 